\title{
Energy efficiency, housing, equity and health
}

\author{
Matthias Braubach • Arnaud Ferrand
}

Published online: 6 January 2013

(C) Swiss School of Public Health 2013

In 2009, $20 \%$ of all European Union (EU) households earning less than $60 \%$ of the national median income faced problems keeping their home warm during the winter time-making them three times more vulnerable to indoor cold than the other households (WHO Regional Office for Europe 2012). Poor households are known to face significant heating expense challenges, and often compromise on indoor temperatures, accepting low thermal comfort due to budgetary constraints (Braubach and Fairburn 2010). Therefore, next to being a climate change priority, policies supporting the refurbishment of energy-inefficient housing should also represent a social and equity priority affecting health and well-being of the residents. However, using the example of thermal insulation of housing as one of the standard measures for energy saving and $\mathrm{CO}_{2}$ emission reduction (Howden-Chapman et al. 2011), the question is raised whether poor households are equally able to participate in and benefit from these policies.

Since many years, the building sector has been identified as one of the key settings for saving energy (UNECE 2009). The focus is put on the residential housing stock which represents up to $26 \%$ of energy needs in the EU (European Environment Agency 2010) and up to $50 \%$ in

\section{Braubach ( $\square)$}

WHO Regional Office for Europe, European Centre for Environment and Health, Hermann-Ehlers-Str. 10, 53113 Bonn, Germany

e-mail: mbr@ecehbonn.euro.who.int

\author{
A. Ferrand \\ Ensap Bx (Bordeaux College of Architecture and Landscape), \\ 740 cours de la Libération, Talence Cedex, BP 70109, \\ Bordeaux 33405, France \\ e-mail: ferrand.arnaud@live.fr
}

the UNECE region (UNECE 2009), depending on the country. One common intervention is the energy-efficient refurbishment of the existing stock which is expected to provide significant energy savings. In the context of such building interventions, the public health community should have vital interest in the social and health-related consequences of housing refurbishment and thermal insulation in relation to fuel poverty and housing risk factors, such as dampness and indoor cold (WHO 2011). Dampness and indoor cold have been associated with excess cardiovascular mortality, respiratory and allergic diseases, asthma and poor mental health, but also affect quality of life in general. Fuel poverty is also considered an indirect risk to health as it affects the budget spent on e.g. personal hygiene, healthy diet, etc.

Most national governments have implemented financial and fiscal incentive programmes promoting thermal retrofitting of the existing housing stock. These programmes support building renovation mostly through reduced interest rates for loans and direct grants, but the relative contribution of grants is often marginal (usually around 5-10\% of total costs). Mainly, the investment is expected to pay off through reduced heating costs which may, depending on the energy costs, take 10-20 years. Although often living in the most deprived and least energy-effective housing stock, and being most exposed to fuel poverty, poor households will rarely have a realistic chance of participating in these schemes to achieve better housing, lower heating costs and indirectly, better health conditions.

A descriptive analysis of selected national energyefficiency support programmes carried out in 2011 across Europe, US and Japan indicates that countries developed different approaches to thermal insulation of housing which can be roughly categorized into three main approaches: 
- Retrospective housing renovation of large parts of the existing housing stock to meet current energy-efficiency requirements through thermal insulation and more effective heating systems. The main criterion for eligibility is building age, with cut-offs chosen for buildings built before 1995 (Germany), 1996 (Luxembourg) or 2000 (Switzerland). This means that $80-90 \%$ of the stock are eligible-irrespective of the energy performance of the building or the social situation of the residents.

- Focus on priority problems: some approaches focus on the most problematic housing stock segments and/or on energy-vulnerable households not being able to afford to keep warm at a reasonable cost (e.g. France, United Kingdom, United States). Intervention measures are thermal insulation, improved heating systems and direct grants for heating costs.

- Prospective innovation focus: some approaches show a focus on technology and clean energy production (e.g. Japan or Spain). Energy-efficiency is then strongly related to renewable and sometimes rather sophisticated energy technologies, which is often strongly associated with new construction rather than the existing stock.

It is obvious that the mitigation of existing social inequalities related to energy demand and energy costs for home heating are not a priority consideration in many national campaigns, and may lead to an increase of social inequalities in energy poverty and risk exposure that is likely to have a negative impact on health inequalities that is difficult to assess. Ongoing European research projects such as URGENCHE (2012) and PURGE (2012) currently attempt to quantify the health impact of climate change policies, including those related to energy-efficiency and thermal insulation. It will be of interest to see whether and to what extent the consequences of such policies will differ across socio-economic groups.

To avoid that well-intended interventions for the public good are implemented to the disadvantage of the most vulnerable, many countries could further explore the benefits of targeted approaches focusing on substandard housing and/or poor households. However, more targeted national campaigns may provide benefits for both the sides as they tackle the problem where it is most relevant (substandard and energy-inefficient housing, generating higher energy savings) and most detrimental (economically vulnerable households where equity and health benefits may be highest). If well-implemented, equity-based housing stock rehabilitation could, thus, maximize its contribution to energy saving and $\mathrm{CO}_{2}$ emission reduction, to social equity and cohesion, and-in the end-to less environmental burden and better health in the least well-off population groups (Braubach 2011).

\section{References}

URGENCHE. Website http://www.urgenche.eu/. Accessed 15 Oct 2012

Braubach M (2011) Key challenges of housing and health from WHO perspective. Int J Public Health 56:579-580

Braubach M, Fairburn J (2010) Social inequalities in environmental risks associated with housing and residential location-a review of evidence. Eur J Public Health 20:36-42

European Environment Agency (2010) Final energy consumption by sector (EN16). EEA, Copenhagen. http://www.eea.europa.eu/dataand-maps/indicators/en16-final-energy-consumption-by-sector/ en16-final-energy-consumption-by-sector. Accessed 15 Oct 2012

Howden-Chapman P et al (2011) Improving health and energy efficiency through community-based housing interventions. Int J Public Health 56:583-588

PURGE. Website http://purge.lshtm.ac.uk/project. Accessed 15 Oct 2012

UNECE (2009) Green Homes: towards energy-efficient housing in the United Nation Economic Commission for Europe region. United Nations Economic Commission for Europe (UNECE), Geneva. http://www.unece.org/fileadmin/DAM/publications/oes/ greenhomes.e.pdf. Accessed 15 Oct 2012

WHO (2011) Health and the Green Economy: health co-benefits of climate change mitigation-Housing sector. World Health Organization, Geneva. http://whqlibdoc.who.int/publications/2011/ 9789241501712_eng.pdf. Accessed 15 Oct 2012

WHO Regional Office for Europe (2012) Environmental health inequalities in Europe. Assessment report. WHO Regional Office for Europe, Copenhagen. http://www.euro.who.int/_data/assets/ pdf_file/0010/157969/e96194.pdf. Accessed 15 Oct 2012 